\title{
Gasotransmitters and Stomatal Closure: Is There Redundancy, Concerted Action, or Both?
}

\author{
Denise Scuffi, Lorenzo Lamattina and Carlos García-Mata * \\ Laboratorio de Fisiologia Molecular e Integrativa, Instituto de Investigaciones Biologicas-CONICET, Universidad Nacional de \\ Mar del Plata, Mar del Plata, Argentina
}

Keywords: gasotransmitter, nitric oxide, hydrogen sulfide, guard cell signaling

OPEN ACCESS

Edited by:

Agepati S. Raghavendra,

University of Hyderabad, India

Reviewed by:

Kapuganti J. Gupta,

University of Oxford, UK

Huyi He,

Guangxi Academy of Agricultural

Sciences, China

*Correspondence:

Carlos García-Mata

camata@mdp.edu.ar

Specialty section: This article was submitted to

Plant Physiology,

a section of the journal

Frontiers in Plant Science

Received: 07 December 2015

Accepted: 21 February 2016

Published: 15 March 2016

Citation:

Scuffi D, Lamattina $L$ and García-Mata C (2016)

Gasotransmitters and Stomatal Closure: Is There Redundancy,

Concerted Action, or Both?

Front. Plant Sci. 7:277.

doi: 10.3389/fpls.2016.00277
The epidermis of the aerial part of land plants is pierced by pores through which plants perform gas exchange with environment. The guard cells (GCs), the specialized cells that surround the pore, have the capacity to sense diverse environmental and endogenous stimuli and integrate them into a single output which is the regulation of the stomatal pore width. The stomatal pore size is modulated by changes of the guard cell volume, driven by variations in the osmotic potential of the GCs.

The stress hormone abscisic acid (ABA), the master regulator of stomatal movement, induces stomatal closure by the inhibition of $\mathrm{H}^{+}$-ATPases and activation of rapid and slow anion channels, producing the depolarization of the plasma membrane (PM) in GCs, and by an increase in the cytosolic $\mathrm{Ca}^{2+}$ concentratrion $\left[\mathrm{Ca}^{2+}\right]_{\text {cyt }}$. While the rise of the $\left[\mathrm{Ca}^{2+}\right]_{\text {cyt }}$ blocks the influx of $\mathrm{K}^{+}$by the inactivation of the inward rectifying $\mathrm{K}^{+}$channels $\left(\mathrm{K}_{\mathrm{in}}^{+}\right)$, the depolarization of the $\mathrm{PM}$, in turn promotes $\mathrm{K}^{+}$efflux driven by outward rectifying $\mathrm{K}^{+}$channels $\left(\mathrm{K}_{\text {out }}^{+}\right.$; Blatt, 2000). This process is closely regulated by a complex signaling network that involves the participation of numerous ubiquitous signaling components like ROS, protein kinases, phospholipases, and protein phosphatases (Kim et al., 2010; Song et al., 2014); and by other signaling components that are emerging as active players in this signaling network, such is the case of gasotransmitters (García-Mata and Lamattina, 2013).

A gasotransmitter is a small gas molecule that: (i) can freely permeates biological membranes; (ii) it is endogenously generated by specific enzymes; (iii) it has specific functions at physiologically relevant concentrations; (iv) it functions can be mimicked by exogenous application of a donor; and (v) it has specific cellular and molecular targets (Wang, 2002). The group of gasotransmitters is, so far, composed by Nitric Oxide (NO), Carbon Monoxide (CO), and Hydrogen Sulfide $\left(\mathrm{H}_{2} \mathrm{~S}\right)$ and the three of them have been reported to participate in the promotion of stomatal closure (García-Mata and Lamattina, 2013), however, the biology of CO in this physiological process is less known than that of $\mathrm{NO}$ and $\mathrm{H}_{2} \mathrm{~S}$. Therefore, this opinion will be focused mainly on the action and interaction of $\mathrm{NO}$ and $\mathrm{H}_{2} \mathrm{~S}$. The two of them are accepted as active players in the regulation of stomatal movement, however there are still obscure points and some of them will be discussed in this opinion article: (i) their specific molecular targets; (ii) the molecular mechanisms underpinning their action; (iii) the interplay between them during the stomatal closure induction; and (iv) the crossed-regulation of their metabolism.

All the three gasotransmitters are synthesized during the promotion of stomatal closure. CO is synthesized via the activity of heme oxygenase (Shekhawat and Verma, 2010). In Vicia faba $\mathrm{CO}$ induces stomatal closure in a dose-dependent manner and acts upstream of the production of NO during ABA-dependent stomatal closure (Cao et al., 2007; She and Song, 2008). It has been reported that the hormones $\mathrm{ABA}$ and ethylene (Eth) require the production of $\mathrm{NO}$ for the regulation of stomatal movement (García-Mata and Lamattina, 2002; Neill et al., 2002; He et al., 2011; Song et al., 2011). NO can be synthesized either from $\mathrm{NO}_{2}$ by two genes, NIA1 
and NIA2, that code for a nitrate reductase (NR), or from Larginine in a reaction catalyzed by an enzyme with nitric oxide synthase (NOS)-like activity, even though the involved enzyme named AtNOA1 possesses GTPase activity (Moreau et al., 2008). However, it was reported that the Arabidopsis triple mutant nia1/nia2/atnoa1, which produces very low levels of NO, is hypersensitive to ABA (Lozano-Juste and León, 2010), suggesting that $\mathrm{NO}$ could have a dual role in $\mathrm{ABA}$-dependent responses. Moreover, it has been found that increased levels of $\mathrm{NO}$ are dependent on the NADPHox-dependent production of $\mathrm{H}_{2} \mathrm{O}_{2}$ (Bright et al., 2006). NO levels can also be modified by an Alternative Oxidase (AOX). Tobacco plants lacking AOX show high NO levels that impacts in stomatal function (Cvetkovska et al., 2014). Recently García et al. (2010) have shown that Arabidopsis mutant plants in $\beta$-Cyanoalanine synthase (Cys-C1), a mitochondrial enzymatic source of $\mathrm{H}_{2} \mathrm{~S}$, show higher $A O X 1 a$ transcript levels than wild type, however exogenous application of $\mathrm{H}_{2} \mathrm{~S}$ to rice cell culture induced AOX expression (Xiao et al., 2010). Further physiological studies are needed to clarify this interaction.

$\mathrm{H}_{2} \mathrm{~S}$ is produced during the passage of L-cysteine to pyruvate and ammonia in a reaction catalyzed by L-cysteine desulfhydrase (DES1; Alvarez et al., 2010). In Arabidopsis there are three different genes involved in this reaction: the DES1 gene (Alvarez et al., 2010; Scuffi et al., 2014), the At-LCDES gene (Jin et al., 2011), and L-CDes gene (Hou et al., 2013). Recently, it has been shown that the expression of these genes is upregulated in response to $\mathrm{ABA}$, Eth, JA, and $\mathrm{SA}$, all hormones that modulate stomatal movement (Hou et al., 2013). Even if sequence analysis has shown that the promoter region of the DES1 gene contains ABA-responsive elements (Scuffi et al., 2014), further work is needed in order to have a better understanding about the mechanism by which these hormones induce the expression of those genes. Although, DES1 was reported to mediate ABAdependent stomatal closure (Scuffi et al., 2014), it was recently reported that $\mathrm{H}_{2} \mathrm{~S}$ regulates the activity of $\mathrm{K}_{\text {in }}^{+}$channel mostly in an $\mathrm{ABA}$ - and $\mathrm{Ca}^{2+}$-independent manner, suggesting the existence of ABA-regulated signaling pathways that can be, alternatively, activated in response to other stimuli (Papanatsiou et al., 2015).

\section{NO PHYSIOLOGY IN GUARD CELLS}

More than a decade of work on the participation of $\mathrm{NO}$ on the regulation of stomatal movement resulted in a more or less bounded idea of its mechanism of action, in particular in those events triggered by ABA. As stated above, ABA-dependent ROS production induces NO synthesis via NR/NOS-like activities. NO regulates the activity of $\mathrm{K}_{\text {in }}^{+}$either via the $\mathrm{Ca}^{2+}$ release from intracellular $\mathrm{Ca}^{2+}$ stores, or through the production of phospholipase D (PLD)-dependent inositol phosphates. Another molecular target of $\mathrm{NO}$ is the soluble guanylate ciclase (sGC) that generates cyclic guanosine monophosphate (cGMP) which is converted to 8 -nitroguanosine $3^{\prime}, 5^{\prime}$-cyclic monosphosphate (8nitro-cGMP) by NO, modulating the $\left[\mathrm{Ca}^{2+}\right]_{\text {cyt }}$ (Joudoi et al., 2013). Recently, it has been proposed that NO may break the
ABA signaling in guard cells. On the one hand NO mediates ABA-dependent stomatal closure via the regulation of $\mathrm{K}^{+}$and $\mathrm{Cl}^{-}$channels (Garcia-Mata et al., 2003; Sokolovski et al., 2005), on the other hand it was suggested that NO can act as a negative regulator of ABA pathway via $S$-nitrosylation of the SnrK2,6/OST1 (Wang et al., 2015) and through the nitration of a Tyr residue of the PYR/PYL/RCAR ABA receptor complex (Castillo et al., 2015).

\section{$\mathrm{H}_{2}$ S PHYSIOLOGY IN GUARD CELLS}

This first report of the participation of $\mathrm{H}_{2} \mathrm{~S}$ in guard cell signaling appeared in 2010, and since then several works have shown that this gasotransmitter induces stomatal closure in different plant species (García-Mata and Lamattina, 2010; Hu et al., 2014; Papanatsiou et al., 2015). In Arabidopsis, DES1 produces $\mathrm{H}_{2} \mathrm{~S}$ in response to $\mathrm{ABA} . \mathrm{H}_{2} \mathrm{~S}$, in turn, increases endogenous $\mathrm{NO}$ production (Scuffi et al., 2014). $\mathrm{H}_{2}$ S-dependent stomatal closure is impaired in the nial/nia2 double mutant. Moreover, the expression of both genes was reported to be upregulated by $\mathrm{H}_{2} \mathrm{~S}$ donors, suggesting that $\mathrm{NR}$ is involved in $\mathrm{H}_{2} \mathrm{~S}$-dependent $\mathrm{NO}$ production (Scuffi et al., 2014). However, Lisjak et al. (2010, 2011) showed that exogenous addition of $\mathrm{H}_{2} \mathrm{~S}$ decreased ABAdependent $\mathrm{NO}$ production and thus induced stomatal opening. Interestingly, it was reported that $\mathrm{H}_{2} \mathrm{~S}$ also modulates Ethdependent stomatal closure, but in this particular case, $\mathrm{NO}$ was reported to act upstream of $\mathrm{H}_{2} \mathrm{~S}$ (Liu et al., 2011; Hou et al., 2013).There are other components, beside NR, that were pointed as targets of $\mathrm{H}_{2} \mathrm{~S}$ during stomatal closure induction, among them: (i) the member of the multidrug resistance protein family AtMRP5, which was proposed as a modulator of $\mathrm{Ca}^{2+}$ and anion channels (Suh et al., 2007; García-Mata and Lamattina, 2010); (ii) 8-nitro cGMP, which reacts with $\mathrm{H}_{2} \mathrm{~S}$ to form 8-mercapto cGMP to modulate $\left[\mathrm{Ca}^{2+}\right]_{\text {cyt }}$ (Honda et al., 2015); and (iii) $\mathrm{K}_{\text {in }}^{+}$channels, which are inactivated by $\mathrm{H}_{2} \mathrm{~S}$ in an ABA-independent manner (Papanatsiou et al., 2015).

\section{THE INTERPLAY BETWEEN NO AND $\mathrm{H}_{2} \mathrm{~S}$}

The gasotransmitters $\mathrm{NO}$ and $\mathrm{H}_{2} \mathrm{~S}$ not only share physicochemical similarities but they can also interact with each other in different biological systems and physiological conditions. Even though, there is still much to learn about: (i) the chemical nature of these interactions, (ii) the different products that can be potentially formed in vivo from the interaction, and (iii) the different biological outcomes. The study of the interaction between different gasotransmitters has kept the attention of researchers from different fields. As a result, different kinds of interactions have been described. There are interactions in which different gasotransmitters can act on the same molecular targets but having either the same or sometimes opposite outcomes (Mustafa et al., 2009b). An example of this in plants is the case of ABA-dependent induction of stomatal closure, where it has been reported that, on the one hand, $\mathrm{ABA}$ induces $\mathrm{H}_{2} \mathrm{~S}$ production which in turn increases endogenous NO levels triggering stomatal closure (García-Mata and Lamattina, 
2010; Scuffi et al., 2014), while on the other hand, it is reported that exogenous addition of $\mathrm{H}_{2} \mathrm{~S}$ decreases ABA-dependent $\mathrm{NO}$ production, thereby producing the opening of the stomatal pore (Lisjak et al., 2010, 2011). There are other crosstalks in which different gasotransmitters produce the same outcome but acting on different molecular targets (Coletta et al., 2012). Such is the case of the regulation of guard cell $\mathrm{K}^{+}$channels, where both NO and $\mathrm{H}_{2} \mathrm{~S}$ selectively inactivate $\mathrm{K}_{\mathrm{in}}^{+}$, however $\mathrm{NO}$ does this through a response that involves the release of $\mathrm{Ca}^{2+}$ from intracellular stores (Garcia-Mata et al., 2003), while $\mathrm{H}_{2} \mathrm{~S}$ inactivates $\mathrm{K}_{\text {in }}^{+}$, mostly in an ABA and $\mathrm{Ca}^{2+}$ independent manner (Papanatsiou et al., 2015).

$\mathrm{H}_{2} \mathrm{~S}$ and $\mathrm{NO}$ can also regulate each other source, by modulating the enzymatic production of the other. In animal systems $\mathrm{H}_{2} \mathrm{~S}$ is able to down regulate $\mathrm{NO}$ production by inhibiting both constitutive and inducible NOS isoforms (Kubo et al., 2007) or to upregulate endothelial NOS (eNOS) dependent NO production (Predmore et al., 2011). In plants, it has been suggested that $\mathrm{H}_{2} \mathrm{~S}$ induces NR-dependent NO production via the regulation of both NIA1 and NIA2 genes (data accessible at NCBI GEO database, accession GSE32566). The cross regulation of gasotransmitter sources has been also shown in the opposite sense. Zhao et al. (2001) have shown that NO donors upregulate the expression of the animal enzymatic $\mathrm{H}_{2} \mathrm{~S}$ source, cystathionine- $\gamma$-lyase (CSE) and its consequent $\mathrm{H}_{2} \mathrm{~S}$ production. In plants $\mathrm{NO}$ also upregulates $\mathrm{H}_{2} \mathrm{~S}$ production during Ethinduced stomatal closure by increasing the expression of $A t L$ CDes/AtD-CDes genes (Liu et al., 2011, 2012).

The gasotransmitters can directly modify their specific targets by posttranslational modification (PTM) of the target protein. Nitric oxide can react with the thiol group of a cysteine residue to form S-nitrosocysteines residues (R-SNO) in a process known as $\mathrm{S}$-nitrosylation, while $\mathrm{H}_{2} \mathrm{~S}$ forms a persulfide group (R-SSH) in a process known as S-sulfhydration. There are proteins that can be modified by both gasotransmitters at the same cysteine residue. Interestingly, sulfhydration and nitrosylation can influence the protein function in different manners, S-nitrosylation modifications usually results in the inactivation of the protein while S-sulfhydration of the protein in many cases results in activating the biological function of the protein (Mustafa et al., 2009a; Jiang et al., 2010). Two examples of the different effects of the PTM in plants are the enzymes ascorbate peroxidase (APX) and glyceraldehydes-3P-dehydrogenase (GAPDH) whose activities are affected in different senses when they are Snitrosylated or S-sulfhydrated, enabling enzymes play additional functions due to PTMs processes (Aroca et al., 2015).

The study of the interaction between $\mathrm{H}_{2} \mathrm{~S}$ and $\mathrm{NO}$ is one of the current challenges for understanding the biology of these two gasotransmitters. The current knowledge shows that these two gases can interact at different stages of the signaling process, at different levels of their biosynthetic pathways and depending of the metabolic and redox status of the target cells (Cortese-Krott et al., 2014, 2015a; Lo Faro et al., 2014).

The existence of a direct chemical reaction between $\mathrm{NO}$ and $\mathrm{H}_{2} \mathrm{~S}$ has gained strength in recent years. It is speculated that this interaction may result in the formation of some novel forms of nitrosothiols not yet fully characterized. In a recent paper, Cortese-Krott et al. (2015b) proposed that the interaction of $\mathrm{NO}$ and $\mathrm{H}_{2} \mathrm{~S}$ would result in the formation of bioactive products at physiological $\mathrm{pHs}$, emphasizing the formation of nitrosopersulfide $\left(\mathrm{NO}^{-}\right)$, polysulfides $\left(\mathrm{HS}_{\mathrm{n}}\right)$, and $\mathrm{N}$-nitrosohydroxylamine-N-sulfonate (SULFI/NO). These compounds could regulate the bioavailability of $\mathrm{NO}$ and $\mathrm{H}_{2} \mathrm{~S}$ by either the releasing or scavenging of each of them, which is depending on the relative concentrations of each one and the redox status of the cell (Cortese-Krott et al., 2015a) In a simplified schematic representation, Figure 1, we summarize the interplay and the close association existing between $\mathrm{NO}$ and $\mathrm{H}_{2} \mathrm{~S}$, and the formation of potential intermediates that could be involved in the regulation of guard cell physiology. These new discovered molecular forms might potentially explain the conflicting results concerning the roles of $\mathrm{NO}$ and $\mathrm{H}_{2} \mathrm{~S}$ of influencing stomatal movement.

\section{CONCLUSIONS}

The details of the biochemical interaction between $\mathrm{NO}$ and $\mathrm{H}_{2} \mathrm{~S}$ are scarcely known in guard cells and in plant systems in general, in comparison to some physiological processes in animal systems (Kolluru et al., 2013; Lo Faro et al., 2014; Cortese-Krott et al., 2015a). However, the evidences presented in this study indicate that both gases can modulate stomatal movement acting independently, or in concerted action, in and ABA-triggered

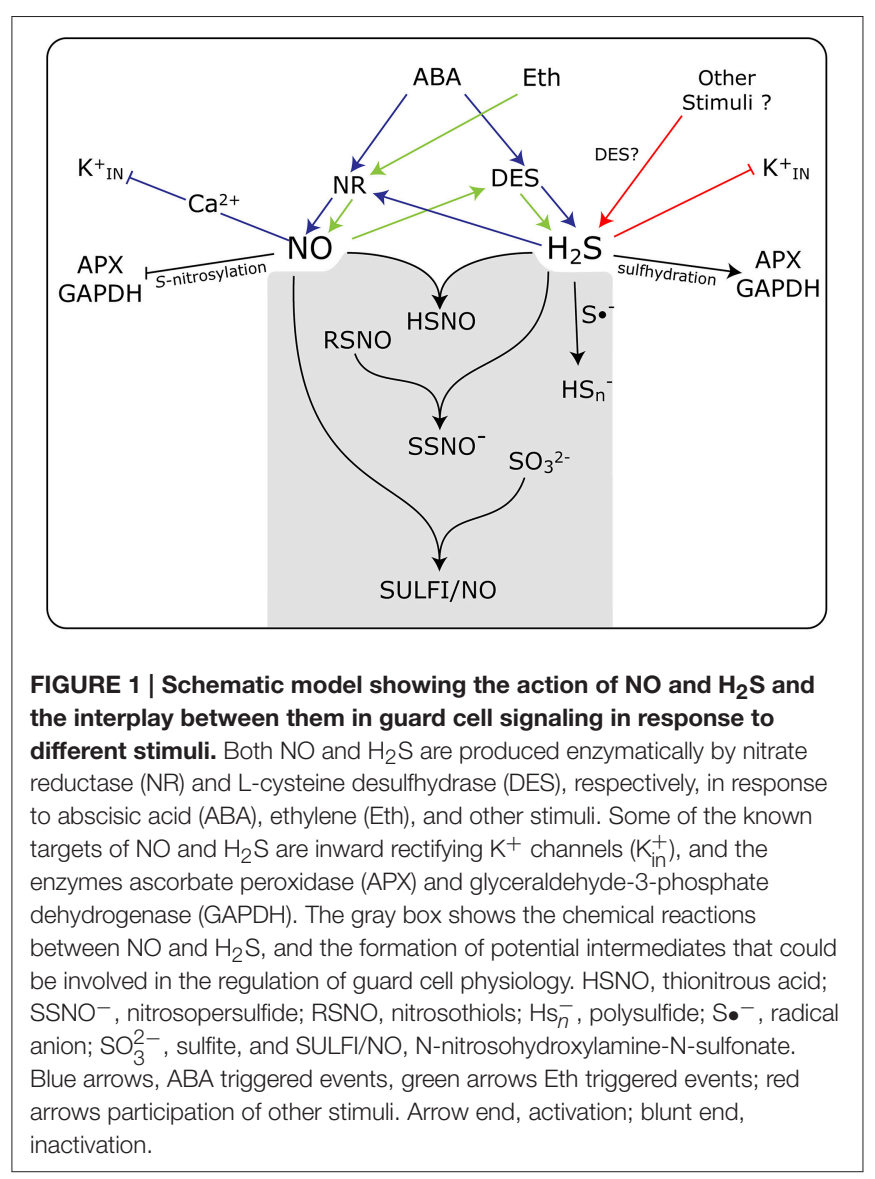


signaling cascade, or in ABA-independent manner. They can modulate the activity of the same molecular target by PTM of cysteine residues, and can even regulate the production and/or bioavailability of each other. In conclusion, it arises the point of the need to be cautious when drawing conclusions about the effects of either $\mathrm{NO}$ or $\mathrm{H}_{2} \mathrm{~S}$, unless the effect of both are studied together at the same biological conditions.

\section{AUTHOR CONTRIBUTIONS}

Both DS and LL contributed in the writing of the manuscript, LL also contributed to give shape the idea of the opinion. CG

\section{REFERENCES}

Alvarez, C., Calo, L., Romero, L. C., García, I., and Gotor, C. (2010). An O-acetylserine(thiol)lyase homolog with L-cysteine desulfhydrase activity regulates cysteine homeostasis in Arabidopsis. Plant Physiol. 152, 656-669. doi: 10.1104/pp.109.147975

Aroca, Á., Serna, A., Gotor, C., and Romero, L. C. (2015). S-sulfhydration: a cysteine posttranslational modification in plant systems. Plant Physiol. 168, 334-342. doi: 10.1104/pp.15.00009

Blatt, M. R. (2000). Cellular signaling and volume control in stomatal movements in plants. Annu. Rev. Cell Dev. Biol. 16, 221-241. doi: 10.1146/annurev.cellbio.16.1.221

Bright, J., Desikan, R., Hancock, J. T., Weir, I. S., and Neill, S. J. (2006). ABAinduced NO generation and stomatal closure in Arabidopsis are dependent on $\mathrm{H} 2 \mathrm{O} 2$ synthesis. Plant J. 45, 113-122. doi: 10.1111/j.1365-313X.2005.0 2615.x

Cao, Z., Huang, B., Wang, Q., Xuan, W., Ling, T., Zhang, B., et al. (2007). Involvement of carbon monoxide produced by heme oxygenase in ABAinduced stomatal closure in Vicia faba and its proposed signal transduction pathway. Chin. Sci. Bull. 52, 2365-2373. doi: 10.1007/s11434-007-0358-y

Castillo, M.-C., Lozano-Juste, J., González-Guzman, M., Rodriguez, L., Rodriguez, P. L., and Leon, J. (2015). Inactivation of PYR/PYL/RCAR ABA receptors by tyrosine nitration may enable rapid inhibition of ABA signaling by nitric oxide in plants. Sci. Signal. 8, ra89. doi: 10.1126/scisignal.aaa7981

Coletta, C., Papapetropoulos, A., Erdelyi, K., Olah, G., Módis, K., Panopoulos, P., et al. (2012). Hydrogen sulfide and nitric oxide are mutually dependent in the regulation of angiogenesis and endothelium-dependent vasorelaxation. Proc. Natl. Acad. Sci. U.S.A. 109, 9161-9166. doi: 10.1073/pnas.12029 16109

Cortese-Krott, M. M., Fernandez, B. O., Kelm, M., Butler, A. R., and Feelisch, M. (2015a). On the chemical biology of the nitrite/sulfide interaction. Nitric Oxide 46, 14-24. doi: 10.1016/j.niox.2014.12.009

Cortese-Krott, M. M., Fernandez, B. O., Santos, J. L. T., Mergia, E., Grman, M., Nagy, P., et al. (2014). Nitrosopersulfide (SSNO-) accounts for sustained NO bioactivity of S-nitrosothiols following reaction with sulfide. Redox Biol. 2, 234-244. doi: 10.1016/j.redox.2013.12.031

Cortese-Krott, M. M., Kuhnle, G. G. C., Dyson, A., Fernandez, B. O., Grman, M., DuMond, J. F., et al. (2015b). Key bioactive reaction products of the $\mathrm{NO} / \mathrm{H}_{2} \mathrm{~S}$ interaction are S/N-hybrid species, polysulfides, and nitroxyl. Proc. Natl. Acad. Sci. U.S.A. 112, E4651-E4660. doi: 10.1073/pnas.1509277112

Cvetkovska, M., Dahal, K., Alber, N. A., Jin, C., Cheung, M., and Vanlerberghe, G. C. (2014). Knockdown of mitochondrial alternative oxidase induces the "stress state" of signaling molecule pools in Nicotiana tabacum, with implications for stomatal function. New Phytol. 203, 449-461. doi: 10.1111/nph.12773

García, I., Castellano, J. M., Vioque, B., Solano, R., Gotor, C., and Romero, L. C. (2010). Mitochondrial beta-cyanoalanine synthase is essential for root hair formation in Arabidopsis thaliana. Plant Cell 22, 3268-3279. doi: $10.1105 /$ tpc. 110.076828

Garcia-Mata, C., Gay, R., Sokolovski, S., Hills, A., Blatt, M. R., and Lamattina, L. (2003). Nitric oxide regulates $\mathrm{K}^{+}$and $\mathrm{Cl}^{-}$channels in guard cells through a made most of the writing and the figure and had the original idea.

\section{FUNDING}

This work was financially supported through grants from the Universidad Nacional de Mar del Plata (UNMdP), PIP-240 from Consejo Nacional de Investigaciones Científicas y Técnicas (CONICET), and PICT-2013-3184 and PICT (CM) and PICT2011-2383 (LL) from Agencia Nacional de Promoción Científica y Tecnológica (ANPCyT). CG and LL are researchers from CONICET.

subset of abscisic acid-evoked signaling pathways. Proc. Natl. Acad. Sci. U.S.A. 100, 11116-11121. doi: 10.1073/pnas.1434381100

García-Mata, C., and Lamattina, L. (2002). Nitric oxide and abscisic acid cross talk in guard cells. Plant Physiol. 128, 790-792. doi: 10.1104/pp.011020

García-Mata, C., and Lamattina, L. (2010). Hydrogen sulphide, a novel gasotransmitter involved in guard cell signalling. New Phytol. 188, 977-984. doi: 10.1111/j.1469-8137.2010.03465.x

García-Mata, C., and Lamattina, L. (2013). Gasotransmitters are emerging as new guard cell signaling molecules and regulators of leaf gas exchange. Plant Sci. 201-202, 66-73. doi: 10.1016/j.plantsci.2012.11.007

He, J.-M., Zhang, Z., Wang, R.-B., and Chen, Y.-P. (2011). UV-B-induced stomatal closure occurs via ethylene-dependent NO generation in Vicia faba. Funct. Plant Biol. 38, 293. doi: 10.1071/FP10219

Honda, K., Yamada, N., Yoshida, R., Ihara, H., Sawa, T., Akaike, T., et al. (2015). 8-Mercapto-cyclic GMP mediates hydrogen sulfide-induced stomatal closure in Arabidopsis. Plant Cell Physiol. 56, 1481-1489. doi: 10.1093/pcp/ pcv069

Hou, Z., Wang, L., Liu, J., Hou, L., and Liu, X. (2013). Hydrogen sulfide regulates ethylene-induced stomatal closure in Arabidopsis thaliana. J. Integr. Plant Biol. 55, 277-289. doi: 10.1111/jipb.12004

Hu, K.-D., Tang, J., Zhao, D.-L., Hu, L.-Y., Li, Y.-H., Liu, Y.-S., et al. (2014). Stomatal closure in sweet potato leaves induced by sulfur dioxide involves $\mathrm{H} 2 \mathrm{~S}$ and NO signaling pathways. Biol. Plant. 58, 676-680. doi: 10.1007/s10535-0140440-7

Jiang, B., Tang, G., Cao, K., Wu, L., and Wang, R. (2010). Molecular mechanism for H(2)S-induced activation of K(ATP) channels. Antioxid. Redox Signal. 12, 1167-1178. doi: 10.1089/ars.2009.2894

Jin, Z., Shen, J., Qiao, Z., Yang, G., Wang, R., and Pei, Y. (2011). Hydrogen sulfide improves drought resistance in Arabidopsis thaliana. Biochem. Biophys. Res. Commun. 414, 481-486. doi: 10.1016/j.bbrc.2011.09.090

Joudoi, T., Shichiri, Y., Kamizono, N., Akaike, T., Sawa, T., Yoshitake, J., et al. (2013). Nitrated cyclic GMP modulates guard cell signaling in Arabidopsis. Plant Cell 25, 558-571. doi: 10.1105/tpc.112.105049

Kim, T.-H., Böhmer, M., Hu, H., Nishimura, N., and Schroeder, J. I. (2010). Guard cell signal transduction network: advances in understanding abscisic acid, CO2, and Ca2+ signaling. Annu. Rev. Plant Biol. 61, 561-591. doi: 10.1146/annurev-arplant-042809-112226

Kolluru, G. K., Shen, X., and Kevil, C. G. (2013). A tale of two gases: NO and H2S, foes or friends for life? Redox Biol. 1, 313-318. doi: 10.1016/j.redox.2013.0 5.001

Kubo, S., Kurokawa, Y., Doe, I., Masuko, T., Sekiguchi, F., and Kawabata, A. (2007). Hydrogen sulfide inhibits activity of three isoforms of recombinant nitric oxide synthase. Toxicology 241, 92-97. doi: 10.1016/j.tox.2007.08.087

Lisjak, M., Srivastava, N., Teklic, T., Civale, L., Lewandowski, K., Wilson, I., et al. (2010). A novel hydrogen sulfide donor causes stomatal opening and reduces nitric oxide accumulation. Plant Physiol. Biochem. 48, 931-935. doi: 10.1016/j.plaphy.2010.09.016

Lisjak, M., Teklić, T., Wilson, I. D., Wood, M., Whiteman, M., and Hancock, J. T. (2011). Hydrogen sulfide effects on stomatal apertures. Plant Signal. Behav. 6, 1444-1446. doi: 10.4161/psb.6.10.17104 
Liu, J., Hou, L., Liu, G., Liu, X., and Wang, X. (2011). Hydrogen sulfide induced by nitric oxide mediates ethylene-induced stomatal closure of Arabidopsis thaliana. Chin. Sci. Bull. 56, 3547-3553. doi: 10.1007/s11434-011-4819-y

Liu, J., Hou, Z., Liu, G., Hou, L., and Liu, X. (2012). Hydrogen sulfide may function downstream of nitric oxide in ethylene-induced stomatal closure in Vicia faba L. J. Integr. Agric. 11, 1644-1653. doi: 10.1016/S2095-3119(12)60167-1

Lo Faro, M. L., Fox, B., Whatmore, J. L., Winyard, P. G., and Whiteman, M. (2014). Hydrogen sulfide and nitric oxide interactions in inflammation. Nitric Oxide 41, 38-47. doi: 10.1016/j.niox.2014.05.014

Lozano-Juste, J., and León, J. (2010). Enhanced abscisic acid-mediated responses in nia1nia2noa1-2 triple mutant impaired in NIA/NR- and AtNOA1-dependent nitric oxide biosynthesis in Arabidopsis. Plant Physiol. 152, 891-903. doi: 10.1104/pp.109.148023

Moreau, M., Lee, G. I., Wang, Y., Crane, B. R., and Klessig, D. F. (2008). AtNOS/AtNOA1 is a functional Arabidopsis thaliana cGTPase and not a nitricoxide synthase. J. Biol. Chem. 283, 32957-32967. doi: 10.1074/jbc.M804838200

Mustafa, A. K., Gadalla, M. M., Sen, N., Kim, S., Mu, W., Gazi, S. K., et al. (2009a). H2S signals through protein S-sulfhydration. Sci. Signal. 2, ra72. doi: 10.1126/scisignal.2000464

Mustafa, A. K., Gadalla, M. M., and Snyder, S. H. (2009b). Signaling by gasotransmitters. Sci. Signal. 2, re2. doi: 10.1126/scisignal.268re2

Neill, S. J., Desikan, R., Clarke, A., and Hancock, J. T. (2002). Nitric oxide is a novel component of abscisic acid signaling in stomatal guard cells. Plant Physiol. 128, 13-16. doi: 10.1104/pp.010707.shown

Papanatsiou, M., Scuffi, D., Blatt, M. R., and García-Mata, C. (2015). Hydrogen sulphide regulates inward-rectifying $\mathrm{K}+$ channels in conjunction with stomatal closure. Plant Physiol. 168, 29-35. doi: 10.1104/pp.114.256057

Predmore, B. L., Julian, D., and Cardounel, A. J. (2011). Hydrogen sulfide increases nitric oxide production from endothelial cells by an Akt-dependent mechanism. Front. Physiol. 2:104. doi: 10.3389/fphys.2011.00104

Scuffi, D., Álvarez, C., Laspina, N., Gotor, C., Lamattina, L., and Garcia-Mata, C. (2014). Hydrogen sulfide generated by L-cysteine desulfhydrase acts upstream of nitric oxide to modulate abscisic acid-dependent stomatal closure. Plant Physiol. 166, 2065-2076. doi: 10.1104/pp.114.245373

She, X.-P., and Song, X.-G. (2008). Carbon monoxide-induced stomatal closure involves generation of hydrogen peroxide in Vicia faba guard cells. J. Integr. Plant Biol. 50, 1539-1548. doi: 10.1111/j.1744-7909.2008.00716.x

Shekhawat, G. S., and Verma, K. (2010). Haem oxygenase (HO): an overlooked enzyme of plant metabolism and defence. J. Exp. Bot. 61, 2255-2270. doi: $10.1093 /$ jxb/erq074
Sokolovski, S., Hills, A., Gay, R., Garcia-mata, C., Lamattina, L., and Blatt, M. R. (2005). Protein phosphorylation is a prerequisite for intracellular $\mathrm{Ca} 2+$ release and ion channel control by nitric oxide and abscisic acid in guard cells. Plant J. 43, 520-529. doi: 10.1111/j.1365-313X.2005.02471.x

Song, X.-G., She, X.-P., Wang, J., and Sun, Y.-C. (2011). Ethylene inhibits darknessinduced stomatal closure by scavenging nitric oxide in guard cells of Vicia faba. Funct. Plant Biol. 38, 767-777. doi: 10.1071/FP11055

Song, Y., Miao, Y., and Song, C. (2014). Behind the scenes: the roles of reactive oxygen species in guard cells. New Phytol. 201, 1121-1140. doi: 10.1111/nph.12565

Suh, S. J., Wang, Y. F., Frelet, A., Leonhardt, N., Klein, M., Forestier, C., et al. (2007). The ATP binding cassette transporter AtMRP5 modulates anion and calcium channel activities in Arabidopsis guard cells. J. Biol. Chem. 282, 1916-1924. doi: 10.1074/jbc.M6079 26200

Wang, P., Du, Y., Hou, Y.-J., Zhao, Y., Hsu, C.-C., Yuan, F., et al. (2015). Nitric oxide negatively regulates abscisic acid signaling in guard cells by S-nitrosylation of OST1. Proc. Natl. Acad. Sci. U.S.A. 112, 613-618. doi: 10.1073/pnas.1423481112

Wang, R. (2002). Two's company, three's a crowd: can H2S be the third endogenous gaseous transmitter? FASEB J. 16, 1792-1798. doi: 10.1096/fj.02-02 11 hyp

Xiao, M., Ma, J., Li, H., Jin, H., and Feng, H. (2010). Effects of hydrogen sulfide on alternative pathway respiration and induction of alternative oxidase gene expression in rice suspension cells. Z. Naturforsch. C. 65, 463-471. doi: 10.1515/znc-2010-7-808

Zhao, W., Zhang, J., Lu, Y., and Wang, R. (2001). The vasorelaxant effect of H2S as a novel endogenous gaseous KATP channel opener. EMBO J. 20, 6008-6016. doi: 10.1093/emboj/20.21.6008

Conflict of Interest Statement: The authors declare that the research was conducted in the absence of any commercial or financial relationships that could be construed as a potential conflict of interest.

Copyright (C) 2016 Scuffi, Lamattina and García-Mata. This is an open-access article distributed under the terms of the Creative Commons Attribution License (CC BY). The use, distribution or reproduction in other forums is permitted, provided the original author(s) or licensor are credited and that the original publication in this journal is cited, in accordance with accepted academic practice. No use, distribution or reproduction is permitted which does not comply with these terms. 